\title{
A REDE FEDERAL DE ENSINO TÉCNICO E TECNOLÓGICO E SEU RELACIONAMENTO COM PÚBLICOS-ALVO: ALGUMAS QUESTÕES DE IDENTIDADE INSTITUCIONAL
}

\author{
L. M. Silva' e A. A. Albino \\ Instituto Federal de Educação, Ciência e Tecnologia do Sudeste de Minas Gerais - Campus Rio Pomba \\ lucas.moreira.silva@live.com ${ }^{1}$
}

Artigo submetido em agosto/2013 e aceito em agosto/2013

\section{RESUMO}

O presente estudo visou investigar a interação da rede federal de ensino técnico e tecnológico com seus públicos-alvo, aqui definidos como: servidores recémcontratados; outras escolas; alunos e seus pais; prefeituras; empresas; associações filantrópicas; ONGs; ou seja, toda e qualquer entidade que tenha interesse na participação em atividades realizadas por essas instituições de ensino. Buscou-se com isso, pesquisar se há utilização de ferramentas que facilitem esse relacionamento e por quais meios isto se faz. Trata-se de um estudo de caso com abordagem predominantemente qualitativa, que permitiu concluir que o relacionamento da rede federal de ensino técnico não apresenta uma estrutura organizacional preparada para se comunicar tanto com os membros internos quanto com os agentes sociais. Espera-se que esta pesquisa desperte nos gestores educacionais a importância que os canais de comunicação representam para a garantia de resultados satisfatórios.

PALAVRAS-CHAVE: Rede Federal de Ensino Técnico e Tecnológico; Identidade e Imagem Institucional; Comunicação.

\section{THE FEDERAL NET OF TECHNICAL AND TECHNOLOGICAL TEACHING AND HIS RELATIONSHIP WITH AUDIENCES: SOME SUBJECTS OF INSTITUTIONAL IDENTITY}

\begin{abstract}
The present study sought to investigate the interaction of the federal net of technical and technological teaching with their audiences, here defined as: newly servants; other schools; students and their parents; city halls; companies; philanthropic associations; NGOs; in other words, all and any entity that has interest in the participation in activities accomplished by those educational institutions. It was looked for with that, search if there is use of tools that facilitate that relationship and for which means this is made. This is a
\end{abstract}

case study with predominantly qualitative approach, which allowed to conclude that the relationship of the federal net of technical teaching doesn't present a prepared organizational structure to communicate so much with the internal members and the social agents both. It is waited that this research awaking in the education managers the importance that the communication channels to represent for the satisfactory results. 


\section{A REDE FEDERAL DE ENSINO TÉCNICO E TECNOLÓGICO E SEU RELACIONAMENTO COM PÚBLICOS-ALVO: ALGUMAS QUESTÕES DE IDENTIDADE INSTITUCIONAL}

\section{INTRODUÇÃO}

A realização do Fórum Mundial de Educação Profissional e Tecnológica, em Brasília no ano de 2009, foi o marco das comemorações do centenário das escolas da Rede Federal, ano marcado também pela consolidação dos Institutos Federais de Educação, Ciência e Tecnologia. Criados em 2008, a partir dos Centros Federais de Educação Tecnológica (CEFETS) e das Escolas Agrotécnicas Federais, os Institutos Federais estão presentes em todos os estados brasileiros, totalizando 38 instituições.

As novas instituições oferecem ensino médio integrado ao ensino técnico, ensino superior e também cursos de pós-graduação latu senso e strictu sensu. É o que se chama de "itinerário formativo" (Brasil, 2010): a possibilidade de o aluno ingressar no ensino médio e ir até o mestrado ou doutorado. Assim, a troca de conhecimento é maior, pois possibilita o contato de mestres e doutores de alta qualificação com estudantes do ensino médio, por exemplo. Constituem-se como as únicas instituições públicas de ensino a oferecer esse tipo de "formação centralizada".

Essa recente mudança na denominação da rede federal de ensino técnico provocou, de um lado, a unificação nominal de várias instituições, mas por outro, o desconhecimento das modalidades de ensino prestadas (até então, eram pouquíssimas as instituições que ofereciam cursos superiores nas mesmas unidades em que são oferecidas a educação média e técnica).

Podendo-se dizer "recém-criadas", tais instituições de ensino se apresentam na sociedade como novidade, e perderam sua "figura tradicional" devido a essa mudança. Por conta disso, algumas pessoas ainda possuem dúvidas tanto com relação aos serviços prestados por essas organizações (que foram ampliados paralelamente à sua mudança), quanto de seu cunho público. A situação agrava quando se trata de pessoas que possuem menos acesso à informação a intitulação "federal" costuma não as remeterem a um serviço público (gratuito).

Portanto, o presente estudo investigou inicialmente quais são os mecanismos que as referidas instituições têm utilizado para informar a todos os interessados (stakeholders) o que tais instituições representam, quais serviços prestam, e quem pode usufruir desses serviços. Essa ferramenta de comunicação é chamada por Schultz e Hatch (2009) de "gerenciamento da expressão organizacional", cuja razão primeira para sua utilização reside na oportunidade da organização se distinguir de seus competidores.

Num segundo momento, esse trabalho procurou esclarecer como a sociedade enxerga essa nova mudança: a imagem transmitida é a imagem recebida? Quais são os meios de transcender essa imagem? Esse processo de "legitimação", segundo Sartor (2009), surge com a finalidade da instituição "dizer" para os ambientes interno e externo que existe e possui credibilidade, matéria-prima simbólica imprescindível na construção da imagem e da identidade.

Por fim, esta pesquisa pretende checar mais a fundo o relacionamento destas instituições com seu principal público-alvo: os futuros estudantes. Cavalheiro (2008) argumenta que em um ambiente tão imprevisível, uma instituição de ensino não pode esperar passivamente que ela seja procurada apenas por seus produtos (cursos, nível de produção acadêmica), serviços (objetividade, agilidade e soluções) e ativos (campi, laboratórios, infraestrutura etc.). Buscar esses stakeholders é uma forma de gerar um senso de "pertencimento" à organização (Schultz e Hatch, 2009). 


\section{REFERENCIAL TEÓRICO}

Os assuntos que oferecem suporte teórico a este trabalho são: identidade e imagem institucional e marca, enquanto elementos que contribuem para a formação da identidade corporativa. Serão abordados ainda a aplicabilidade da comunicação organizacional e a questão do marketing para instituições de ensino.

\section{Identidade e Imagem}

Uma instituição, pessoa, uma forma de comunicação; enfim, tudo que tem capacidade de expressão possui uma identidade. No sentido literal, identidade diz respeito às características implícitas do emissor. Trata-se de um conceito interno que sofre influência de percepções externas (Ruão, 2002). Obviamente, ela difere dependendo do contexto. No âmbito deste estudo, a identidade a ser estudada será a institucional: a capacidade das organizações se expressarem. Enquanto um sistema de valores, crenças e cultura, as organizações têm na identidade a oportunidade de trespassar o sentido que deseja atribuir a si mesmas.

Portanto, "o entendimento da singularidade da identidade de uma organização (no sentido de que é única, interpretada de diversas formas) pode ser compartilhado não somente entre seus membros, mas por outros indivíduos e grupos que se relacionam com ela" (SILVA E NOGUEIRA, 2001, p. 44), os chamados stakeholders, definidos por Cavalheiro (2008) como sendo os consumidores, fornecedores, parceiros, as instituições e entidades, os formadores de opinião, a mídia, o governo, a concorrência, entre outros.

Porém, a identidade organizacional não sofre influência somente do meio externo. Seus membros (também possuidores de identidade) influenciam a construção da identidade coletiva, principalmente quando há distinções entre elas. "Quando isso ocorre, as ações individuais ou coletivas interrompem o curso normal de funcionamento organizacional, levando os participantes a se questionarem sobre a finalidade e a natureza das suas atividades" (SILVA E NOGUEIRA, 2001, p. 45), ocasionando na pior das hipóteses, o rompimento da relação existente entre o indivíduo e a organização.

Corroborando com Machado (2005), Whetten e Godfrey (1998) e Dutton e Dukerich (1991) já partem do pressuposto de que a identidade organizacional é constituída pela interpretação que os integrantes da organização fazem dela, ressaltando que a percepção externa se trataria da imagem organizacional, admitindo-se, porém, que exista relação complementar entre esses dois fenômenos.

Enquanto geradora de significados, a identidade organizacional passa a integrar o fenômeno semiótico. Sebeok (1976, p. 1) define que "a extensão semiótica e seus assuntos incluem a troca de quaisquer mensagens que sejam e de sistemas de sinais que estejam por baixo deles". Esse processo também pode ser definido como a tentativa da organização se legitimar - "unificar, dar coerência e estabilizar-se de modo a garantir um bom nível de simpatia e identificação públicos-organização através da comunicação" (SARTOR, 2009, p. 7), conferindoIhe autenticidade e visibilidade.

Ao mesmo tempo em que a identidade busca conferir à organização uma característica única, a chamada "institucionalização" afeta essa capacidade. Schultz e Hatch (2009) definem esse fenômeno como sendo um tipo de "imitação", que torna as organizações mais similares em seus valores, símbolos e principalmente em sua identidade, e consequentemente, identificar/diferenciar essas companhias que atuam em um mesmo 
segmento fica mais difícil. Entretanto, esse fenômeno também é uma das formas das organizações se legitimarem, quando incorporam práticas e procedimentos definidos previamente (Meyer e Rowan, 1992).

Outro fenômeno bastante comum que influencia a identidade é a cultura. Este elemento social, quando representa significados para os consumidores, é capaz de dominar ou subordinar projetos corporativos. No contexto das organizações, "possibilita a integração dos aspectos simbólicos às preocupações estratégicas” (RODRIGUES, 1997, p. 47).

Criar um corpo integrado de conhecimento (cultura), pensamento (identidade) e prática (imagem) é um passo necessário para elaborar um conceito que contemple a multiplicidade de relações entre membros, gestores, organização e stakeholders. Afinal, o fluxo dessas relações colapsa as distinções interna-externa e revela a existência de complementaridade e interdependência entre cultura, identidade e imagem. (BORGES E MEDEIROS, 2011, p. 134)

Mas a real intenção da identidade não está em sua manifestação, e sim em sua recepção, principalmente por exigência dos novos mercados. A imagem que a organização deseja passar para seu ambiente externo é fundamental para o sucesso de no alcance de seus resultados.

[...] Pode-se supor que a imagem é um fator inacabado, por ser receptivo e mutante, sempre passível de modificações e de adição de novas informações, podendo alterar ou não o seu significado simbólico, dependendo da forma e constância em que são emitidas novas informações e como são recebidas e percebidas (CARRIERI et al., 2004, p. 27).

Gomes e Sapiro (1993) complementam ainda que a imagem não pode ser tocada, vista ou medida, pois existe somente como um conceito na mente das pessoas, e é composta dos seguintes elementos: experiências, valores, sentimentos, preconceitos, atitudes, observações, crenças e informações (Baptista, 2004). Contudo, pode ser controlada, através do gerenciamento de impressões: "processo desenvolvido para controlar [...] possíveis comportamentos voltados para a criação de 'impressões positivas' de grupos e de organizações como um todo" (MENDONÇA et al., 1999, p. 4).

Muitas vezes as organizações, agindo com dolo, transmitem imagens e constroem reputações que não são coerentes com sua realidade (Mendonça e Andrade, 2003). Esse tipo de ação se constitui de um método da companhia atingir algum objetivo, considerado um "gerenciamento de impressões cínico". Os mesmos autores ainda acreditam que essas ações são invocadas no sentido de se obter publicidade, mas não deixam de ser parte do gerenciamento da imagem da organização.

Baptista (2004) afirma que é possível ter uma boa imagem sem ter uma boa reputação. Para o autor, a reputação é construída ao longo da vida organizacional, substituindo a imagem. Entende-se, portanto, que organizações mais antigas normalmente já possuem uma imagem consolidada na sociedade, que a permite ter certos "privilégios mercadológicos" devido a sua reputação. Pode-se dizer também que a reputação de uma organização é o fator superlativo resultante da imagem.

O conceito de imagem é dividido, de acordo com Santaella e Noth (2008), em:

(1) imagens gráficas - imagens desenhadas, ou pintadas, esculturas; (2) imagens óticas espelhos, projeções; (3) imagens perceptíveis - dados de ideias, fenômenos; (4) imagens 
mentais - sonhos, lembranças, ideias, fantasias; e (5) imagens verbais - metáforas, descrições. (SANTAELLA \& NOTH, 2008, apud SOUZA, 2011, p. 85)

Essa pluralidade de definições proporciona a noção da complexidade do trabalho que as organizações devem desenvolver para gerenciar todos esses elementos, que advém de diversas direções e constroem (ao mesmo tempo em que influenciam) as formas como as companhias vêm se relacionando e comunicando com seus clientes, fornecedores e colaboradores.

Histórias recentes de sucesso de marketing enfatizam o reconhecimento crescente da relação entre imagem e produto, como a Nike, que percebeu que seu negócio não está em vender sapatos, mas de fazer imagem. Esses tipos de organizações comunicam a imagem, não o produto, em suas campanhas comerciais (Firat, 1995).

A próxima sessão faz algumas considerações sobre as marcas: importantes elementos para a identidade organizacional e para o relacionamento da organização com os seus públicosalvo.

\section{Marca}

Assim como a identidade e a imagem, a marca é um dos meios disponíveis para as organizações se manifestarem. Apresentam, aliás, ligação entre si, pois do mesmo modo que uma organização possui identidade, uma marca também possui, e pode inclusive, transmitir imagens - apesar de alguns autores atribuírem a identidade organizacional à identidade da marca. Neste artigo, a identidade/imagem da marca é entendida como um processo de (re)afirmação da identidade organizacional.

A AMA - American Marketing Association (2010) define marca como "um nome, termo, design, símbolo ou qualquer outra característica que identifica um produto ou serviço como distinto de outros".

Para se construir uma marca sólida, deve-se proceder de forma estratégica, analisando o ambiente (consumidor, concorrência e autoanálise), que permita a organização definir os primeiros traços da identidade da marca baseados na identidade organizacional lembrando que a marca não deve representar somente um produto, mas também uma gama de valores organizacionais e atributos do ambiente externo (Sant'Ana, 2012).

Uma marca de qualidade está na essência do que os consumidores estão adquirindo. Assim, está diretamente relacionada com sua identidade (Crescitelli e Figueiredo, 2009). Esses mesmos autores defendem que ela pode ser representada por seu valor, um elemento estratégico que sustenta a posição da organização no mercado, valorizando-a, do mesmo modo que, quando mal gerida, pode debilitar ou desvalorizar a imagem da organização.

Para Lima e Arruda Filho (2012), as pessoas que defendem uma marca tendem a atribuir características negativas às marcas rivais. "Esse tipo de consumidor vive a marca de forma pessoal e afetiva" (Ibidem, p. 9). Se tratando de marcas consolidadas, os esforços de marketing para chegar a esses consumidores são menores, pois o posicionamento que possuem na mente desses consumidores já é o suficiente para leva-los até ela. Porém, quando uma das partes falta com seu compromisso (a marca de gerar significado e o consumidor de ser leal) há uma ruptura de relação.

Segundo Bó et al. (2012, p. 683), "cada vez mais, a chave para o sucesso das organizações parece residir nos benefícios emocionais e de auto expressão que as marcas são capazes de proporcionar aos seus consumidores", permitindo que as mesmas influenciem no 
processo e decisão de compra, ocupando também um lugar na mente desses consumidores. Os mesmos autores então concluem: "a essência do posicionamento consiste em lidar com a forma com que os consumidores percebem os produtos, os serviços, as marcas e as organizações concorrentes" (Ibidem, p. 685). "Para chegar ao topo do grupo e, sobretudo, aí ficar, uma marca deve consumir seus recursos cada vez mais custosos, muito mais que uma posição dominante depende apenas de um desempenho superior relativo" (SEMPRINI, 2006, p. 100).

As expressões da identidade organizacional, juntamente com a marca, tendem a ser mais coerentes através de diferentes serviços e mercados onde servem de exemplo de reconhecimento e confiança. Porém, o fortalecimento de culturas regionais levantam questões de como essas marcas deveriam se portar e adaptar frente a essas culturas (Schultz e Hatch, 2009). Semprini (2006, p. 72), defende ainda que, "pela multiplicidade de suas manifestações, a marca pode variar seus discursos, diferenciar seus objetivos, dirigir-se de forma quase personalizada a cada consumidor", o que evidencia uma preocupação com sua abordagem e as associações feitas.

Uma marca fiel à sua identidade procura manter uma relação profunda e comprometida com seus consumidores. No processo de comunicação, pode-se dizer que a marca é o emissor e os consumidores os receptores. Mas o que dirá para a organização se a marca tem cumprido seu papel e feito jus à sua identidade, será a imagem da marca - conjunto de atributos e associações que os consumidores fazem em relação à marca. Ou seja, o significado que ela representa para cada consumidor.

Por se tratar de significado, a imagem da marca influencia no processo de construção da identidade individual de cada consumidor, pois ela terá um sentido diferente para cada um que adquiri-la. Esse conceito surgiu a partir da evolução do processo de compras; onde antes se comprava benefícios e qualidade, hoje se adquiri status, símbolos e personalidade. Mas para chegar a tal ponto, o conceito de marca adquiriu dois importantes aspectos que são fundamentais para seu fortalecimento: o branding e o brand equity.

O primeiro, pela própria definição na gramática inglesa, trata-se de um gerúndio de brand, que na prática quer dizer "gerenciamento da marca". Cova (1996) ainda o relaciona com o marketing de imagens, onde ambos são frutos do marketing pós-moderno - por que diferenciam a imagem da marca da concorrência, através da embalagem, nome, apresentação e personalidade da marca.

Schultz e Hatch (2009) afirmam que todos os esforços no sentido de gerar significado para a identidade corporativa são tarefas do branding. Para os mesmos autores, é uma forma de distinguir expressões organizacionais usadas como estratégias. Assim, o branding pode ser considerado como o processo de gestão da marca que irá lhe agregar valor. Esse valor da marca passa então a ser conhecido como brand equity.

"O termo brand equity se refere tanto ao valor econômico de uma marca quanto ao seu valor simbólico, e trata da dialética proveniente da interação desses valores" (SANT'ANA, 2012, p. 54). Também pode ser entendido como uma forma de compensação pelos esforços do branding e do marketing de imagens (Crescitelli e Figueiredo, 2009; Cova, 1996). A mensuração desse aspecto evolutivo da marca se torna importante à medida que as ações de marketing e branding surtem efeito.

O valor de uma marca é fixado pela "taxa de desejo" ou pela "força de sonho" que ela sabe introduzir em seus públicos. Estas taxas não são necessariamente afetadas pela difusão quantitativa da marca: ao contrário, os mecanismos gregários e a força normativa da moda só multiplicam o valor de uma marca que "todo mundo disputa". 
Naturalmente, estes fenômenos se comportam de forma diferente, conforme setores [...]. (SEMPRINI, 2006, p. 98)

Independente do valor econômico ou simbólico, o brand equity é um dos ativos (mais importantes) que as organizações dispõem para sua solidificação no mercado, pois está claramente ligado à importância que o consumidor tem pela marca. Em troca, os consumidores anseiam por experiências que enfatizem interatividade, conectividade e criatividade - onde deixam de ser manipulados para serem envolvidos no processo de comunicação (Cova, 1996).

Num modelo proposto por Crescitelli e Figueiredo (2009), o branding seria o responsável por gerir tanto a marca (brand) quando o seu valor agregado (brand equity). Por outro lado, podemos entender o brand equity como o resultado do branding sobre a marca (brand). Portanto, essa variabilidade de interpretações enfatiza o intenso entrosamento entre a marca (identidade), seu valor para o consumidor (imagem) e a comunicação existente entre ambos - capacidade de um gerar sentido para outro.

\section{Comunicação Organizacional}

O processo de comunicação muitas vezes é confundido com publicidade. De fato, este último é um dos meios de uma organização se relacionar com um público-alvo. Mas a comunicação organizacional vai muito além de uma interação entre empresa-cliente: concorrentes, fornecedores, entidades, órgãos públicos, ONGs, grupos de defesa ambiental etc., fazem parte de um ambiente onde a organização precisa se preocupar com as mensagens que transmite, para que não seja mal interpretada por nenhum desses agentes. "Pode-se considerar a publicidade como uma modalidade de expressão da marca, ao passo que a comunicação abrange o conjunto das modalidades por meio das quais ela se manifesta" (SEMPRINI, 2006, p. 82). Tratase de estratégias de ajustamento ao ambiente externo (Mendonça e Andrade, 2003).

\footnotetext{
Estar em um meio de comunicação é obrigatório. Não é preciso utilizar-se das grandes mídias como televisão, rádio, jornal e revista para dizer "eu existo". Expor a marca ao público em patrocínios [...] ou em causas sociais implicam em uma maneira de se impor na sociedade (Sion et al., 2011).
}

A comunicação corporativa tem focado principalmente em como as organizações contam histórias para stakeholders (internos e externos) sobre quem são, o que fazem e como fazem (Schultz e Hatch, 2009). Pelos diversos meios existentes - muitos deles interativos, há uma constante busca por um relacionamento quase que personalizado com os indivíduos, posicionando-os de forma a contribuir para a construção (bilateral) da relação (Semprini, 2006).

O papel desempenhado pela comunicação serve de avaliação para a sociedade quanto à utilidade e à legitimidade das atividades das organizações (Mendonça e Andrade, 2003). Falhas no processo de comunicação podem impactar diretamente na imagem e na identidade da marca - ou da organização: quando a primeira não reflete fielmente a segunda, há uma ruptura de papéis, impactando diretamente nas estratégias e ações desenvolvidas (Sant'Ana, 2012).

Um dos meios que a organização tem para controlar o que deve ser informado ao seu público é a assessoria de imprensa: uma ramificação do setor de relações públicas no qual os dirigentes selecionam o que deve (e o que não deve) ser repassado aos stakeholders a cerca das atividades praticadas. Uma assessoria de imprensa rápida e constantemente atualizada também é capaz de dar à organização um suporte a respeito do que tem sido falado sobre ela. [...] Possui 
papel relevante no sentido de contribuir para aquisição de credibilidade, por que atua na tentativa de conquistar a visibilidade midiática por meio do discurso informativo (Sartor, 2009).

É através da visibilidade midiática que as organizações buscam justificar suas ações e disputar o apoio ou a simpatia da opinião pública: os meios de comunicação (re)produzem os diversos discursos sociais e assim oferecem o ambiente em que as atitudes individuais e coletivas são publicamente explicadas (SARTOR, 2009, p. 3).

As organizações também usam web sites corporativos, blogs e outros tipos de presença virtual para comunicar sobre elas mesmas, e convidar stakeholders a dialogarem. Com relação a isso, cada vez mais companhias estão se tornando comunidades on line - associação de consumidores ou outros tipos de eventos onde stakeholders podem se relacionar mais regularmente com a organização e cada qual pode expressar sua opinião, convicções e experiências adquiridas, e exaltar a lógica de marca (Schultz e Hatch, 2009; Semprini, 2006). Embora o meio digital seja muito importante na busca de envolvimento com stakeholders externos, ele também pode oferecer grandes oportunidades dos empregados se relacionarem entre si.

Comunicação integrada é o conjunto de ações ordenadas e coordenadas para fortalecer a imagem da instituição, permitindo uma visibilidade positiva entre os diversos públicos que interagem; criando um espírito interno de cooperação e estimulando a compra de um serviço. (RAINHO, 2008, p. 132)

"Vale destacar que os esforços de comunicação realizados não garantem a obtenção da imagem desejada" (MENDONÇA E ANDRADE, 2003, p. 11). As estratégias de comunicação devem, assim, desempenhar importante função potencializadora, fornecendo elementos que permitam aos públicos construírem uma apreciação positiva o mais próximo possível das idealizações e estratégias institucionais (Sartor, 2009).

Nesse novo contexto, será ferramenta decisiva o processo de planejamento institucional, viabilizando uma comunicação mais eficiente entre os diversos níveis da estrutura administrativa e oportunizando tomada de decisões mais rápidas e em consonância com as prioridades e a função social dos Institutos Federais. (FERNANDES, 2009, p. 9)

\section{Marketing Educacional}

A utilização das ferramentas do marketing empresarial na área educacional começou quando diversas instituições perceberam a necessidade de não mais ir atrás de seu público-alvo, mas sim fazê-lo com que fosse até elas. Na prática, o que diferencia o marketing educacional do praticado pelas empresas é apenas o ramo de atuação (Facó, 2008).

Assim, da mesma maneira em que no ambiente corporativo há a grande incidência de concorrência, no âmbito escolar também ocorre esse fenômeno, causado principalmente pela intenção governamental de democratizar o acesso ao ensino superior e pela necessidade das instituições de se "atualizarem" para sobreviverem em um mercado crescentemente mutável (Facó, 2008).

Seguindo os parâmetros empresariais, as instituições de ensino devem focar constantemente as necessidades e inclinações do mercado, sendo importante estudar o que está sendo desenvolvido em termos de marketing, como por exemplo, as formas de promoção dos 
processos seletivos e a percepção que se tem de seus públicos-alvo (Bronnemann e Silveira, 2002).

\begin{abstract}
No Brasil, temos hoje uma instabilidade política no que diz respeito à área da educação. Com forte regulamentação e políticas que se alteram rapidamente, o ensino torna-se refém da falta de um planejamento adequado. A dicotomia entre público e privado torna-se latente a cada instante, e pressões de vários agentes chocam-se continuamente, impossibilitando a categoria de entender clara e detalhadamente o mercado no qual está inserida. (FACÓ, 2008, p. 27)
\end{abstract}

Complementando a afirmação de Facó, Martins (1989, p. 42) ainda ressalta que "as condições ambientais impuseram às IES a tarefa de repensar sua atuação, e de redefinir suas diretrizes e instrumentos de ação". Bronnemann e Silveira (2002, p. 2) acreditam que esses instrumentos devem "agregar valor ao mix de serviços educacionais da instituição, no sentido de que sejam percebidos, claramente, os benefícios que serão obtidos pelo mercado-alvo, com a aquisição e consumo dos serviços daquela instituição de ensino, em específico". Silva e Añez (2010) ressaltam que a conjuntura econômica, atrelada a novos meios de produção e relações trabalhistas, provocaram novas demandas educacionais, exigindo das instituições profissionais atualizados e novas ofertas de ensino.

[...] o aluno quer receber um serviço educacional sério e de qualidade, oferecido por um corpo docente qualificado e capacitado, assessorado por funcionários treinados e motivados, com instalações adequadas e, obviamente, ver o nome da sua escola projetado entre as melhores. (COLOMBO, 2004 apud SION, 2011, p. 3)

Martins (1989) ainda salienta que, se bem empregadas, as ações de marketing contribuirá para a validação e legitimação da instituição de ensino, sendo vistas além de seu tradicionalismo ou reputação, mas também pelo papel que representa na sociedade. A adoção dessas ações provavelmente trará para a instituição mudanças drásticas e revolucionárias, onde os diretores terão de vê-las mais como reflexo do contexto social do que uma ameaça de perda de identidade.

Conclui-se então, que a instituição de ensino deve ficar atenta aos rumos que segue para satisfazer a infinita gama de stakeholders que a cerca, pois quando bem definido o posicionamento que a instituição quer ter, terá assim construída toda a sua estratégia de gestão (Cavalheiro, 2008).

\title{
METODOLOGIA
}

É possível caracterizar esta proposta de pesquisa como descritiva, com abordagem predominantemente qualitativa. Para Cervo e Bervian (2002 p. 67), uma pesquisa descritiva "trata-se do estudo e da descrição das características, propriedades ou relações existentes na comunidade, grupo ou realidade pesquisada". Gil $(2008$, p. 176) define a análise qualitativa como uma "redução, seleção e simplificação dos dados [...], de acordo com os temas ou padrões definidos nos objetivos originais da pesquisa".

O meio de investigação da primeira etapa foi a pesquisa documental, que, segundo Gil (2008, p. 51), apesar de assemelhar-se à pesquisa bibliográfica, difere na natureza das fontes, visto que "a pesquisa documental vale-se de materiais que não receberam ainda um tratamento analítico, ou que ainda podem ser reelaborados de acordo com os objetivos da pesquisa". 


\section{Objeto e Sujeitos do Estudo}

Para a primeira fase da investigação, de caráter documental, todas as instituições da Rede Federal de Educação Profissional, Científica e Tecnológica de Minas Gerais representaram o objeto de estudo desta proposta, totalizando 58 unidades. O Quadro 01 apresenta a distribuição dos Institutos Federais (IF), Cefets e escolas vinculadas às universidades presentes no estado, as quais se configuram como objeto de estudo desta proposta. Cabe ressaltar que as informações do site do MEC são diferentes daquelas encontradas nos sites das reitorias, apresentando-se não muito atualizadas, uma vez que não mostram os campi recém-inaugurados.

Quadro 01: Institutos Federais, CEFETs e escolas técnicas vinculadas às universidades federais em Minas Gerais.

\begin{tabular}{|c|c|c|}
\hline Instituição & Campus & Unidades \\
\hline $\begin{array}{l}\text { Instituto Federal do Norte } \\
\text { de Minas Gerais }\end{array}$ & $\begin{array}{l}\text { Montes Claros, Januária, Salinas, Pirapora, Araçuaí, } \\
\text { Arinos, Almenara, Teófilo Otoni, Diamantina. }\end{array}$ & 9 \\
\hline $\begin{array}{l}\text { Instituto Federal do Sudeste } \\
\text { de Minas Gerais }\end{array}$ & $\begin{array}{l}\text { Juiz de Fora, Muriaé, Rio Pomba, Barbacena, Santos } \\
\text { Dumont, São João Del-Rei, Bom Sucesso, Manhuaçu. }\end{array}$ & 8 \\
\hline $\begin{array}{l}\text { Instituto Federal de Minas } \\
\text { Gerais }\end{array}$ & $\begin{array}{l}\text { Ouro Preto, Congonhas, São João Evangelista, Betim, } \\
\text { Sabará, Governador Valadares, Bambuí, Ribeirão das } \\
\text { Neves, Ouro Branco, Formiga. } \\
\text { Unidades Conveniadas: João Monlevade, Pompéu, } \\
\text { Piumhí, Oliveira. }\end{array}$ & 14 \\
\hline $\begin{array}{l}\text { Instituto Federal do Sul de } \\
\text { Minas }\end{array}$ & $\begin{array}{l}\text { Inconfidentes, Machado, Muzambinho, Passos, Poços } \\
\text { de Caldas, Pouso Alegre. }\end{array}$ & 6 \\
\hline $\begin{array}{l}\text { Instituto Federal do } \\
\text { Triângulo Mineiro }\end{array}$ & $\begin{array}{l}\text { Ituiutaba, Paracatu, Uberaba, Uberlândia (2 unidades), } \\
\text { Patrocínio }\end{array}$ & 6 \\
\hline $\begin{array}{c}\text { CEFET } \\
\text { (Centro Federal de } \\
\text { Educação Tecnológica) }\end{array}$ & $\begin{array}{l}\text { Unidades de Ensino Descentralizadas: } \\
\text { Araxá, Divinópolis, Leopoldina, Nepomuceno, Timóteo, } \\
\text { Contagem, Curvelo, Varginha, Belo Horizonte I, Belo } \\
\text { Horizonte II, Belo Horizonte III }\end{array}$ & 11 \\
\hline $\begin{array}{l}\text { Escolas Técnicas Vinculadas } \\
\text { à Universidades Federais }\end{array}$ & $\begin{array}{l}\text { Escola Técnica de Saúde (ESTES) - UFU; Centro de } \\
\text { Formação Especial em Saúde - UFTM; Colégio Técnico } \\
\text { do Centro Pedagógico (COLTEC) - UFMG; Central de } \\
\text { Ensino e Desenvolvimento Agrário - UFV. }\end{array}$ & 4 \\
\hline \multicolumn{2}{|r|}{ Total } & 58 \\
\hline
\end{tabular}

Fonte: Baseado nos dados das Reitorias dos Campi.

Compondo um segundo momento da pesquisa, foi elaborado um questionário semiestruturado, onde foram abordadas questões referentes às informações coletadas na literatura pesquisada e nos sítios institucionais. Para uma base mais profunda, foi utilizada a técnica de entrevista focalizada na instituição de origem do projeto que tem como resultado este artigo.

As demais instituições foram consultadas, uma a uma, via e-mail e telefone (quando necessário), através do Setor de Comunicação de cada reitoria e posteriormente de cada campus. 
Os campi que não possuíam este setor foram contatados através da seção responsável pela extensão universitária. Assim, foram contatados 37 campi, dentre os quais somente 14 retornaram o questionário proposto. Esse número pode ser considerado válido, já que houve a participação de ao menos duas unidades das 5 Reitorias dos Institutos Federais e do CEFET do estado de Minas Gerais. O contato apenas não foi possível com as Escolas Técnicas Vinculadas às Universidades, pois não apresentaram opções de contato atualizadas em seus portais, seja por e-mail ou por telefone.

\section{Instrumento de coleta de dados}

O Quadro 02 apresenta os principais elementos abordados na pesquisa, que auxiliaram na pesquisa documental, bem como nortearam a elaboração das perguntas presentes no questionário aplicado.

Quadro 02: Abordagem teórica

\begin{tabular}{|c|l|l|}
\hline $\begin{array}{c}\text { Principal assunto } \\
\text { investigado }\end{array}$ & \multicolumn{1}{|c|}{ Questões referentes à: } & \multicolumn{1}{c|}{ Fonte } \\
\hline $\begin{array}{c}\text { Relacionamento } \\
\text { com públicos-alvo }\end{array}$ & $\begin{array}{l}\text { Visitas a outras escolas, divulgação } \\
\text { de processos seletivos, realização de } \\
\text { eventos; }\end{array}$ & $\begin{array}{l}\text { Sion, (2011), Schultz e Hatch } \\
\text { (2009), Semprini (2006), } \\
\text { Bronnemann e Silveira } \\
\text { (2002), Martins (1989). }\end{array}$ \\
\hline $\begin{array}{c}\text { Consolidação da } \\
\text { imagem institucional }\end{array}$ & $\begin{array}{l}\text { Participação em eventos, projetos } \\
\text { extensionistas, sinalização, utilização } \\
\text { dos canais de comunicação local e } \\
\text { virtual, comunicação interna, relação } \\
\text { com outros campi; }\end{array}$ & $\begin{array}{l}\text { Humphreys (2010), Sebeok } \\
\text { (1976), Schultz e Hatch } \\
\text { (2009), Meyer e Rowan } \\
\text { (1992), Sant'ana (2012), } \\
\text { Santaella e Noth (2008), } \\
\text { Martins (1989). }\end{array}$ \\
\hline $\begin{array}{c}\text { Relacionamento } \\
\text { com agentes sociais } \\
\text { (stakeholders) }\end{array}$ & $\begin{array}{l}\text { Servidores recém-contratados, } \\
\text { prefeituras e empresas, associações } \\
\text { diversas. }\end{array}$ & $\begin{array}{l}\text { Silva e Nogueira (2001), } \\
\text { Cavalheiro (2008), Machado } \\
\text { (2005), Semprini (2006), } \\
\text { Schultz e Hatch (2003), } \\
\text { Sartor (2009), Martins } \\
\text { (1989). }\end{array}$ \\
\hline
\end{tabular}

Fonte: Elaborado pelos autores.

\section{Análise dos dados}

Os resultados da pesquisa foram analisados por meio da técnica da Análise de Conteúdo, que, para Bardin (2009) é uma técnica para o tratamento de dados que busca identificar o que está sendo dito a respeito de determinado tema. A mesma autora a define como:

Um conjunto de técnicas de análise das comunicações visando a obter, por procedimentos sistemáticos e objetivos de descrição do conteúdo das mensagens, indicadores (quantitativos ou não) que permitam a inferência de conhecimentos relativos às condições de produção e recepção (variáveis inferidas) destas mensagens. (BARDIN, 2009, p. 44) 
As categorias pertinentes aos propósitos da pesquisa podem ser definidas como classes que reúnem um grupo de elementos sob um título genérico, sendo o agrupamento gerado em razão dos caracteres comuns desses elementos (Ibidem, 2009). 0 ato de categorizar significa isolar elementos para, em seguida, agrupá-los.

Gil (2008) descreve que a análise qualitativa consiste em reduzir os dados coletados (seleção e simplificação), apresentá-los (organizá-los e analisá-los sistematicamente) e por fim concluí-los/verifica-los para considerar seus significados.

\section{RESULTADOS E DISCUSSÕES}

Com base nas informações coletas nos sítios institucionais e na literatura pesquisada, o questionário elaborado foi dividido em três grupos. O primeiro questionou o relacionamento das instituições com os públicos-alvo; o segundo indagou quais ferramentas as instituições dispõem para a consolidação de sua imagem; e o terceiro tratou mais especificamente dos estudantes externos.

O Quadro 03 apresenta suscintamente os campi que se disponibilizaram a responder o questionário.

Quadro 03: Instituições pesquisadas

\begin{tabular}{|c|c|c|c|c|c|c|}
\hline \multicolumn{7}{|c|}{ Instituições } \\
\hline & CEFET MG & $\begin{array}{c}\text { IF } \\
\text { Norte MG }\end{array}$ & $\begin{array}{c}\text { IF } \\
\text { Sudeste MG }\end{array}$ & $\begin{array}{c}\text { IF } \\
\text { Sul de Minas }\end{array}$ & IF MG & $\begin{array}{l}\text { IF Triângulo } \\
\text { Mineiro }\end{array}$ \\
\hline Campi & $\begin{array}{c}\text { Belo } \\
\text { Horizonte, } \\
\text { Curvelo e } \\
\text { Divinópolis }\end{array}$ & Salinas & $\begin{array}{c}\text { Muriaé, } \\
\text { Rio Pomba e } \\
\text { Santos Dumont }\end{array}$ & $\begin{array}{l}\text { Poços de } \\
\text { Caldas e } \\
\text { Machado }\end{array}$ & $\begin{array}{c}\text { Formiga e } \\
\text { Ouro } \\
\text { Branco }\end{array}$ & $\begin{array}{c}\text { Ituiutaba, } \\
\text { Patrocínio e } \\
\text { Uberaba } \\
\text { (Unidade II) }\end{array}$ \\
\hline
\end{tabular}

Fonte: Elaborado pelos autores.

\section{Relacionamento com públicos-alvo}

Com relação aos servidores recém-contratados, a maioria das instituições não possuem um programa desenvolvido especialmente para a integração dos mesmos. Grande parte realiza uma apresentação informal da estrutura física e organizacional do Campus. Destaca-se um programa desenvolvido por uma das instituições, onde os servidores são acolhidos pela Associação da categoria, conjuntamente com o Setor de Gestão de Pessoas, demonstrando ao recém-contratado uma preocupação do campus em recebê-los da melhor maneira possível. Na avaliação geral, grande parte dos respondentes avaliou essa relação como boa.

Quando questionados sobre a relação com os pais dos alunos, os respondentes afirmaram que o contato ocorre de maneira constante. Pode-se atribuir esta periodicidade principalmente ao fato das instituições receberem alunos menores de idade, o que implica na criação de um vínculo entre pais e educadores no acompanhamento da vida acadêmica do aluno mais forte do que se observa em cursos de graduação ou pós-graduação. Buscando aprimorar este contato, uma das instituições desenvolveu um software on line onde os pais possuem acesso ao rendimento escolar de seus filhos. Nas demais, o contato é feito através do setor de 
Assistência Estudantil. A avaliação desse relacionamento por parte dos respondentes variou entre bom e muito bom.

Foi também averiguado o vínculo das instituições com as prefeituras das cidades onde os campi estão instalados. Todas as instituições consultadas possuem convênios ou parcerias com as prefeituras, desde a cessão de imóveis e servidores, oportunidades de estágios para os alunos, desenvolvimento de projetos em escolas municipais, até a melhoria dos acessos viários e espaços públicos no entorno das instituições. Esse vínculo entre prefeitura e campus foi avaliado como bom/muito bom por mais da metade das instituições.

A relação das empresas da região com as instituições também foi investigada. Como no caso das prefeituras, todos os campi possuem algum vínculo com empresas, seja para o caso de prestação de serviços ou fornecimento de produtos. Relacionam-se também pela questão da cessão de estágio aos alunos. Uma das instituições, inclusive, oferece cursos de aperfeiçoamento aos funcionários de uma empresa. Esse quesito também foi avaliado como bom por mais da metade dos respondentes.

Por fim, quando foram questionadas a respeito do relacionamento com associações de qualquer natureza, nem todas possuem algum tipo de parceria. Nesse caso em específico, as associações tornam-se ferramenta de desenvolvimento e difusão de projetos e trabalhos que pregam o voluntariado, principalmente entre os alunos; porém menos da metade incentiva os alunos a realizarem atividades que envolvam estas entidades. Essa pouca participação dos alunos parece denotar baixa preocupação do desenvolvimento de pessoas, onde o profissional é visto como prioridade. Mas ainda sim, a grande maioria avaliou esse vinculo entre instituição e associações como bom.

\section{Consolidação da imagem institucional}

Nesta segunda parte do questionário, foram apresentados às instituições alguns mecanismos de expressão organizacional, e em seguida, as instituições foram questionadas acerca de quais destes mecanismos utilizam para, além de se comunicarem, fortalecerem sua presença na região.

O primeiro questionamento se relacionou com a participação da instituição em eventos (regionais ou não). Esse tipo de participação gera no público presente uma ideia da importância dada pela instituição ao público, através do seu comportamento e exposição da imagem. Todas as instituições respondentes alegaram participar de exposições, congressos estudantis e tecnológicos, feiras técnicas em outras instituições de ensino, além de fóruns e feiras regionais. Já com relação à divulgação dos processos seletivos nestes eventos, todas as instituições afirmaram que utilizam esse espaço para tal finalidade. Na avaliação geral, não houve unanimidade: duas instituições avaliaram que a participação em eventos é ruim, bem como outras duas avaliaram como sendo regular e ótimo; três avaliaram como sendo bom e muito bom, e apenas uma avaliou como excelente (uma das instituições não respondeu).

Em seguida, foi questionado se os projetos e atividades desenvolvidas pelas instituições eram divulgados para a comunidade local. Apenas uma instituição não divulga a realização dessas atividades. O restante faz esse tipo de difusão, inclusive por meio dos canais de comunicação em massa da região (TV e rádio). Pode-se ainda atribuir o uso da comunicação em massa ao fato de 9 das 14 instituições possuírem parceria com os meios de comunicação local. Como uma segunda causa, o fato de a grande maioria das instituições estarem instaladas em pequenas cidades contribui para o uso desses canais, concluindo que a minoria utiliza dos canais 
virtuais. Assim, a avaliação de mais da metade dos respondentes variou entre boa e ótima a divulgação de trabalhos realizados na comunidade.

A questão da sinalização dos campi também foi abordada. Metade dos respondentes considerou que a presença da instituição na cidade é perceptível através da sinalização existente; cinco delas responderam que não há sinalização indicando onde a instituição está instalada, onde uma ainda frisou o fato de a sinalização só estar presente em tempos de processo seletivo; outras duas consideraram razoável a sinalização existente. A sinalização pode ser considerada como um dos meios menos burocráticos e onerosos para uma instituição se manifestar. Considerando o fato de alguns tipos de sinalização ser permanentes e de pouca manutenção, podem ser o suficiente para instituições instaladas em cidades de pequeno porte. Algumas instituições avaliaram sua sinalização, portanto, como péssimo ou ruim - menos da metade considerou boa.

Foi apresentado aos respondentes o grau de participação da instituição em redes sociais. Quase todas utilizam desse canal, e não somente para a divulgação de processos seletivos - utilizam também para informar sobre as atividades realizadas na instituição, editais, eventos, notícias, lembretes aos alunos, para contato com ex-alunos, divulgar oportunidades de empregos, estágios etc. Uma delas utiliza apenas nos períodos de processo seletivo, e outra não possui páginas nas redes sociais. Assim como a sinalização, a utilização de redes sociais também é um dos meios menos dispendiosos para a instituição, podendo inclusive gerar resultados mais significativos que outros de menor alcance e mais caros. A grande maioria avaliou a utilização desse canal entre bom e ótimo.

Quando indagados acerca da divulgação interna dos projetos realizados pelos alunos, todos responderam que há algum tipo de difusão dessa informação - por qualquer meio que seja, ainda que informalmente ou boca a boca. Esse tipo de contato e comunicação interna pode ser importante para um melhor clima organizacional, bem como pode influenciar diretamente na cultura - e a longo prazo na identidade da instituição - além do fato de que os membros da organização (alunos ou servidores) percebem que o papel que desempenham ali dentro está surtindo efeito de alguma forma. A grande maioria dos respondentes avaliou essa comunicação interna entre boa e ótima.

Finalizando este tópico, os respondentes foram questionados sobre a relação do campus com outros campi (da mesma rede ou não). A grande maioria respondeu que o contato com outras instituições se dá principalmente para a troca de experiências, tendo em vista que o recente plano de expansão da rede federal de ensino técnico fez com que muitas instituições fossem criadas. Assim, o contato se dá com aquelas que já possuem mais tempo de existência. Além disso, o contato é feito para a realização conjunta de projetos de pesquisa e extensão, realização de eventos, elaboração de materiais, padronização de comunicação etc. Salientamos a parceria entre o IF de Poços de Caldas com o IFSP, onde o segundo oferece cursos de pósgraduação para os servidores do primeiro. Na avaliação geral, boa parte dos respondentes considerou bom e outros consideraram muito bom esse tipo de relacionamento.

\section{Relacionamento com estudantes de outras instituições}

O último tópico do questionário investigou a existência de relação entre os campi e os alunos de outras escolas. Vale ressaltar que esses estudantes tratam-se daqueles com potencial para serem alunos da própria instituição pesquisada.

Quando perguntados sobre como a instituição se comunicava com estes estudantes, a grande maioria indicou que é por meio dos eventos citados anteriormente que acontece esse 
contato, sendo que algumas realizam ainda visitas nas escolas para a divulgação de processos seletivos. Avaliaram, portanto, esse contato como regular. Das que realizam visitas, metade incentiva a participação de alunos nesse processo de divulgação nas escolas, a outra metade não. O uso de estudantes da própria instituição para divulgá-la é bem vindo em vários sentidos: pela proximidade que os estudantes conseguem atingir com relação a outros estudantes, fato que pode ser destacado pela linguagem, por exemplo; pelo fato de ser algo espontâneo e, na grande maioria das vezes, feito de modo gratuito e por uma fonte qualificada, no sentido de ser o público que tem grande chance de ser compreendido pelos alunos potenciais, entre outros. A utilização dos estudantes da instituição como recurso para sua divulgação demonstra que o aluno também faz parte da construção da identidade institucional.

Além das visitas nas escolas, as instituições utilizam de outros meios para divulgar processos seletivos e chegar a esses estudantes. Rádio, TV, jornais, panfletos, outdoors e páginas em redes sociais compõem uma gama de ferramentas disponíveis e que são usadas pelas instituições. Quanto maior a diversidade de uso desses canais, maiores são as chances das instituições obterem resultados significativos. Mais da metade considerou boa a utilização desses materiais.

Mas não é somente a instituição que tem o dever de procurar seus futuros alunos: estes também devem procurar saber e (se possível) participar de eventos realizados por ela. Assim, para finalizar, os respondentes foram indagados da realização de eventos (tais como Mostra de Cursos, Feiras Estudantis dentro da própria instituição, entre outros) para esclarecer para todos os interessados quais cursos oferecem, bem como projetar melhor a imagem da instituição. Apesar de um pouco mais da metade ter sinalado que realiza com certa periodicidade eventos para divulgar suas atividades, um número expressivo de instituições responderam que não realizam eventos com esses fins. Nesse sentido, o campus Poços de Caldas está finalizando um projeto de criação de uma Mostra Virtual das Profissões, que ficará disponível permanentemente no site da instituição, aberto a todos os interessados. Uma forma prática e acessível para quem se interessa pelos cursos oferecidos pela instituição. Como nos demais, esse quesito foi avaliado pela maioria como bom e ótimo.

\section{CONCLUSÃO}

Primeiramente, percebeu-se que poderia haver mais a inclusão dos alunos em alguns processos da instituição. Além do benefício acadêmico, a instituição passa a demandar do aluno uma responsabilidade que só seria cobrada depois de formado - fato que pode ser encarado como um processo de construção da identidade individual, influenciada pela identidade da instituição. Portanto, a identidade individual de cada aluno seria a imagem percebida (por qualquer agente social) da identidade institucional.

Com relação à estrutura das instituições, percebeu-se que a maioria não possui um setor de comunicação bem definido. Muitas vezes, um servidor desempenha o cargo ao qual responde e ao de assessor de comunicação. A falta de um órgão como esse pode comprometer a coleta ou difusão de informações tanto dentro quanto fora da instituição. Esse aspecto foi observado principalmente pela dificuldade em se obter informações acerca das instituições para compor esta pesquisa, fato que é inclusive, entendido neste artigo, como a sua principal limitação - dado o fato se somente 14 das instituições participarem efetivamente.

É notório que os serviços oferecidos pelas instituições de ensino não são amplamente divulgados como os processos seletivos. Esse foco direcionado nos dá a impressão de uma instituição que visa quase que exclusivamente a entrada de novos alunos. 
Por outro lado, as instituições que exploram os diversos meios de comunicação estão, além de ampliando a quantidade de espectadores, dando a oportunidade de pessoas menos instruídas terem acesso a informações que muitas vezes são preferencialmente difundidas pela internet. Com isso, a imagem gerada da instituição é positiva ao passo que se mostra mais democrática e acessível a todos.

Sendo assim, pode-se concluir que muitas instituições não se apresentam na sociedade da forma pretendida pela Lei № 11.892 (Brasil, 2008), que institui a criação da rede federal de ensino técnico. No caso específico dos Institutos Federais, "existe um largo caminho a percorrer com vistas ao atendimento dos pressupostos delineados pelo Governo Federal [...], especialmente quanto ao fato de se constituírem com uma identidade única e estrutura multicampi, o que requer uma organização administrativa inovadora com bases próprias de rede" (FERNANDES, 2009, p. 5).

\section{REFERÊNCIAS BIBLIOGRÁFICAS}

1. AMA. American Marketing Association's Dictionary. Disponível em: <http://www.marketingpower.com/_layouts/Dictionary.aspx?dLetter=B >. Acesso em: 02/08/2013.

2. BAPTISTA, S. G. A importância do estudo sobre a imagem organizacional para as unidades de informação e para seus gestores. Biblios, v. 5, n. 18-19, p. 48-59, set. 2004.

3. BARDIN, L. Análise de Conteúdo. Edições 70. 2009.

4. BÓ, G. D. et al. O endosso por celebridade e a gestão da imagem da marca: Evidências empíricas a partir do estudo da marca Ipanema Gisele Bündchen. REAd, ed. 73, n. 3, p. 681717, Porto Alegre, 2012.

5. BORGES, J. F.; MEDEIROS, C. R. O. "Aprecie com moderação": A Identidade da organização como drama e atos de performance. RAE. São Paulo, v. 51, n. 2, p. 132-142, 2011.

6. BRASIL, Ministério da Educação. Institutos Federais: Uma conquista de todo os brasileiros. Disponível em: <http://portal.mec.gov.br/dmdocuments/folheto_setec.pdf>. Acesso em: 19/05/2013.

7. BRASIL. Lei № 11.892 de 29 de Dezembro de 2008. Casa Civil. Disponível em: <http://www.planalto.gov.br/ccivil_03/_ato2007-2010/2008/lei//11892.htm>. Acesso em: 03/08/2013.

8. BRONNEMANN, M. R.; SILVEIRA, A. Marketing em instituições de ensino superior: A promoção do processo seletivo. Blumenau: 2002.

9. CARRIERI, A. P. et al. Imagem organizacional: um estudo de caso sobre a PUC Minas. Administração em Diálogo, São Paulo, no 6, p. 23-35, 2004.

10. CAVALHEIRO, W. Branding: Gestão da Marca em Instituições de Ensino. In: Marketing Educacional em ação: Estratégias e ferramentas. Porto Alegre: Bookman, Artmed, 2008.

11. CERVO, A. L.; BERVIAN, P. A. Metodologia Científica. 5. ed. São Paulo: Prentice Hall, 2002.

12. COVA, B. What Postmodernism means to Marketing Managers. European Management Journal. Vol. 14, n. 5, p. 494-499, 1996. 
13. CRESCITELLI, E.; FIGUEIREDO, J. B. Brand Equity Evolution: A system dynamics model. Brazilian Administration Review (BAR), v. 6, n. 2, art. 2, p. 101-117. Curitiba, 2009.

14. FACÓ, M. H. A Essência do Marketing Educacional. In: Marketing Educacional em ação: Estratégias e ferramentas. Porto Alegre: Bookman, Artmed, 2008.

15. FERNANDES, F. C. M. Gestão dos Institutos Federais: O desafio do centenário da Rede Federal de Educação Profissional e Tecnológica. Revista Holos, ano 25, vol. 2, 2009.

16. FIRAT, A. F.; DHOLAKIA, N.; VENKATESH, A. Marketing in a postmodern world. European Journal of Marketing, vol. 29, n. 1, p. 40-56, 1995.

17. GIL, A. C. Métodos e técnicas de pesquisa social. 6. Ed. São Paulo: Atlas, 2008.

18. GOMES, M. T.; SAPIRO, A. Imagem corporativa - Uma vantagem sustentável. RAE, n. 33, v. 6, p. 84-96.

19. LIMA, R. M. C.; ARRUDA FILHO, E. J. M. Preferências hedônicas e justificações utilitárias na introdução de novos produtos de alta tecnologia. JISTEM, v.9, n. 1, pp. 171-188, jan./abr. 2012.

20. MACHADO, H. V. Identidade Organizacional: Um estudo de caso no contexto da cultura brasileira. Revista de Administração de Empresas - RAE, v. 4, n. 1, Art. 12, 2005.

21. MARTINS, G. A. Adoção do Marketing pelas Instituições de Ensino Superior. Revista de Administração de Empresas (RAE), vol. 29, n. 3, p. 41-48. São Paulo, 1989.

22. MENDONÇA, J. R. C.; ANDRADE, J. A. Gerenciamento de impressões: Em busca da Legitimidade Organizacional. Revista de Administração de Empresas - RAE, n. 1, vol. 43, p. 3648, 2003.

23. MENDONÇA, J. R. C. et al. Gerenciamento de impressões, comunicações e ações simbólicas como elementos facilitadores na gestão de processos de mudança organizacional. In: 23으 Encontro Anual Da Associação Nacional De Programas De Pós-Graduação Em Administração ANPAD. Anais... Foz do Iguaçu: 1999.

24. MEYER, J. W., ROWAN, B. Institutionalized organizations: formal structures as myth and ceremony. In: MEYER, J. W., SCOTT, W.R. Organizational environments ritual and rationality. London: Sage, 1992. p. 41-62.

25. RAINHO, J. M. Comunicação Integrada: Jornalismo, Relações Públicas e Publicidade. In: Marketing Educacional em ação: Estratégias e ferramentas. Porto Alegre: Bookman, Artmed, 2008.

26. RODRIGUES, S. B. Cultura Corporativa e Identidade: Desinstitucionalização em Empresa de Telecomunicações Brasileira. RAC, v. 1, n. 2, p. 45-72, 1997.

27. RUÃO, T. Uma investigação aplicada da identidade da marca: o caso das porcelanas Vista Alegre. Revista Comunicação e Sociedade, v. 4, n. 1-2, pp. 223 - 242, 2002.

28. SANT'ANA, V. A. Análise semiótica da identidade da marca Chilli Beans. Dissertação (Mestrado) - Departamento de Administração, Pontifícia Universidade Católica do Rio de Janeiro, 2012.

29. SARTOR, B. A. Assessoria de Imprensa e Visibilidade: A Imagem-conceito das Organizações no incontrolável domínio da notícia. In: ABRACORP. São Paulo: 2009. 
30. SCHULTZ, M.; HATCH, M. J. The SAGE Handbook of Organizational Behavior: Managing Organizational Expression. Cap. 22, p.374-390. SAGE Publications Ltd, 2009.

31. SEBEOK, Thomas A. Contributions to the Doctrine of Signs. Indiana University Press. Bloomington: 1976.

32. SEMPRINI, Andrea. A marca pós-moderna: poder e fragilidade da marca na sociedade contemporânea. São Paulo: Estação das Letras Editora, 2006.

33. SILVA, C. L. M.; NOGUEIRA, E. E. S. Identidade Organizacional: Um caso de Manutenção, outro de Mudança. RAC, Edição Especial, p. 35-58, 2001.

34. SILVA, M. E. S. F.; AÑEZ, M. E. M. Coevolução e as práticas isomórficas de gestão: um estudo sobre os processos de mudanças institucionais no Instituto Federal de Educação, Ciência e Tecnologia do RN. Revista Holos, ano 26, vol. 4, 2010.

35. SION, D. E. et al. Marketing Educacional. In: ENCONTRO CIENTÍFICO E SIMPÓSIO DE EDUCAÇÃO UNISALESIANO, 3, 2011. Anais... Lins, 2011.

36. SOUZA, J.M. O impacto que as imagens podem causar na sociedade global: a desconstrução como instrumento de análise. Dissertação (Mestrado) - Instituto de Ciências Sociais, Universidade de Minho, 2011.

Agradecimentos: À Fundação de Amparo à Pesquisa de Minas Gerais (FAPEMIG) pela bolsa de Iniciação Científica, concedida de agosto de 2012 a julho de 2013. 